\title{
Does rugby headgear prevent concussion? Attitudes of Canadian players and coaches
}

\section{J A Pettersen}

Br J Sports Med 2002;36:19-22

\author{
J A Pettersen, University \\ of Toronto, Toronto, \\ Canada \\ Correspondence to: \\ Dr Pettersen, Department of \\ Clinical Neurosciences, \\ Foothills Hospital, \\ 1403-29th Street, NW, \\ Calgary, Alberta, Canada \\ T2N 2T9; \\ Jacqueline.Pettersen@ \\ CalgaryHealthRegion.ca \\ Accepted \\ 15 October 2001
}

\begin{abstract}
Objectives: To examine the attitudes of players and coaches to the use of protective headgear, particularly with respect to the prevention of concussion.

Methods: A questionnaire designed to assess attitudes to headgear was administered to 63 players from four different Canadian teams, each representing a different level of play (high school, university, community club, national). In addition, coaches from all four levels were questioned about team policies and their personal opinions about the use of headgear to prevent concussion.

Results: Although the players tended to believe that the headgear could prevent concussion $(62 \%)$, the coaches were less convinced (33\%). Despite the players' belief that headgear offers protection against concussion, only a minority reported wearing headgear $(27 \%)$ and few $(24 \%)$ felt that its use should be made mandatory. Common reasons for not wearing headgear were "its use is not mandatory", "it is uncomfortable", and "it costs too much".

Conclusion: Although most players in the study believe that rugby headgear may prevent concussion, only a minority reported wearing it. Coaches tended to be less convinced than the players that rugby headgear can prevent concussion.
\end{abstract}

$\mathrm{R}$ ugby is a contact sport in which the potential for injury to the head resulting in concussion is relatively high. ${ }^{1}$ Concussion, as defined by Kelly and Rosenberg ${ }^{2}$ and endorsed by the American Academy of Neurology," is "a traumainduced alteration in mental status that may or may not involve loss of consciousness". While some degree of amnesia and/or confusion is invariably experienced, symptoms such as dizziness, headache, and nausea may or may not be present. Concussion can certainly have an impact on the wellbeing of a player and even temporarily impair cognition..$^{4-8}$ It has been suggested that repeated concussion may irreversibly affect attention $^{9-14}$ and memory. ${ }^{11-14}$ However, prospective studies are lacking and this assertion therefore remains controversial. Regardless of their potential long term effects, rugby related concussions are an important health concern, and effective methods of prevention need to be developed.

Rugby headgear is currently not mandatory, and its use must comply with the standards set down by the International Rugby Board (IRB). Ultimately, it is the referee who determines if a particular piece of headgear is acceptable or not, based on the guidelines. The IRB has recently amended Law 4 (Players' Dress) to include headgear. It states that headgear must be made of soft and thin materials, with no part of the headgear thicker than $1 \mathrm{~cm}$ when uncompressed, no part to have a density $>45 \mathrm{~kg} / \mathrm{m}^{3}$, and headform acceleration must be restricted to 200-550 g in a drop test from 0.3 m. ${ }^{15}$ Several companies, including Rhino, Canterbury, Gilbert, Rugbytech, Mizuno, and Predator, now manufacture headgear that complies with IRB guidelines, which can be found in specialised sports stores across Canada and around the world.

Headgear use is highly variable, with some teams-for example, the Shawnigan Lake High School teams in Victoria, $\mathrm{BC}$-and even one country (Japan) making it mandatory. More typically, the decision to use headgear resides with the individual player. Although it is not currently known how many players world wide choose to wear headgear, Gerrard et $a l^{16}$ reported headgear use by $20 \%$ of rugby players in New Zealand. At that time, it was reported to be mostly limited to forwards and a few backline players who were recovering from an injury or who had been concussed several times in the past.
Nevertheless, its use in Canada appears to be on the rise, with a number of retail stores across the country reporting progressively increasing sales.

The primary reasons for wearing headgear are to prevent lacerations and abrasions to the scalp and to minimise the risk of concussion. ${ }^{17}$ Although it is generally accepted that headgear will prevent surface wounds, it is far less clear whether it will protect against concussion. In fact, because of lack of evidence, the Canadian Rugby Union currently advises against its use to prevent concussion (J Preston Wiley 1998, personal communication). Wilson ${ }^{17}$ reported that anecdotal evidence of the effectiveness of headgear is conflicting, with some people claiming that the protection afforded is negligible. However, he states "headgear was also associated with no concussion incidents in a season when several incidents had been reported in previous seasons." A recent investigation of the attenuation of impact energy of rugby headgear, however, suggests that the current commercially available headgear will not reduce the likelihood of concussion. ${ }^{18}$

Somewhat surprisingly, at the time this study was carried out (early 1999), there had been no previous reports of the attitudes of players or coaches to headgear. To date, there has been only one study, ${ }^{19}$ which assessed the attitudes of under 15 year old schoolboy rugby union players in Australia. The aim of the present study was to determine the attitudes of Canadian players and coaches to the use of protective headgear, particularly with respect to the prevention of concussion.

\section{METHODS}

Two questionnaires, which had been approved by a hospital ethics committee, were used. The players' questionnaire was a multiple choice format. In addition to assessing basic personal data, it assessed attitudes and behaviour using a five point ranking scale: agree strongly, agree, undecided, disagree, disagree strongly. The coaches' questionnaire, which consisted of open ended questions, assessed background information (coaching and playing experience with respect to duration of 
experience at each level), team policies, and personal opinions on the use of headgear. The main reason for the differences in the two questionnaires was the expected discrepancy in the number of participants in each category. It was felt that open ended, rather than closed ended, questions would elicit more useful information from the relatively small group of participating coaches. The relatively large group of players, on the other hand, was less conducive to this form of evaluation.

\section{Procedure}

Coaches of rugby teams at all four levels (high school, university, community club, and national), involving either sex and from either Toronto or Victoria, were contacted by telephone or email in February 1999. They were informed of the purpose of the study and what was expected of them should they and their team members choose to participate. The players' questionnaires were given to the team coaches or trainers to distribute. They were instructed to stress that participation in the study was entirely voluntary and that the respondent's identity would remain confidential (names were not to be written on the questionnaire forms). On completion of the questionnaires, the coaches were to collect them and, without looking at them, place them immediately in a large envelope, which they were to then seal and return to the researcher. These directions were given to help minimise selection bias, to attempt to ensure informed consent, and to promote honest responses from the players.

The coaches' questionnaires were administered according to their preference (by telephone interview, or written and sent by fax, email, or post) with opportunity for clarification of questions by telephone or email.

As the purpose of this study was to obtain information on the attitudes of players and coaches who differed with respect to several variables (geographic location, sex, level of team), descriptive rather than interpretive statistics were used. Discrepancies between teams, where they exist, are noted.

\section{RESULTS}

\section{Basic characteristics}

The players' questionnaire was completed by 63 Canadian rugby players, 39 (62\%) of which were men and 24 (38\%) were women. This is a response rate of 63 of an expected 80 players $(79 \%)$. The players were from four teams, each of which represented a different level of play: high school $(\mathrm{n}=23)$, university $(\mathrm{n}=14)$, community club $(\mathrm{n}=10)$, national $(\mathrm{n}=$ 16). The university team was from Toronto, and the other three were from Victoria. The university and community club teams were composed of female players, and the other two consisted of male players. The ages of the players ranged from 15 to 33, with a mean (SD) age of 19.9 (3.8). The years of experience of playing rugby ranged from 1 to 12 years, with a mean (SD) of $4.9(2.2)$ years.

The coaches' questionnaire was completed by nine Canadian coaches, seven of whom were men. The coaches were from teams at each of the four levels of play: high school $(\mathrm{n}=$ $5)$, four of whom were from Victoria and one from Toronto; university $(\mathrm{n}=2)$, both of whom were from Toronto; community club $(\mathrm{n}=1)$, who was from Victoria; national $(\mathrm{n}=1)$, who was from Toronto. Three of the coaches were from the same teams as the players who completed the players' questionnaire (high school, university, community club). The five other coaches were not actively coaching a team at the time of the study, which was the off season for many teams. Coaching experience ranged from 9 to 20 years (mean 11.8 years), and playing experience ranged from 5 to 40 years (mean 16.4). With respect to team policies, only one of the nine coaches (who was not actively coaching at the time of the study) reported that headgear was mandatory.

\section{Players' attitudes to safety gear}

Overall, the players' questionnaire showed that, although most players believed that headgear can protect against concussion, most did not wear it and did not believe that its use should be made mandatory.

Headgear was used by only 17 (27\%) of the 63 players. Most of these, 10 of the 17 (59\%) were from the national team. In fact, $62 \%$ of the national team reported using headgear, whereas only $26 \%$ of the high school team, $10 \%$ of the community club team, and none of the university team reported its use.

Almost half of the players (49\%) either disagreed or disagreed strongly that headgear should be worn by all rugby players; however, $27 \%$ were undecided and 24\% agreed or agreed strongly. While this pattern describes most of the teams, the community club team was more in favour of wearing headgear, with $60 \%$ reporting that they agreed or agreed strongly that headgear should be worn by all players.

Although most players did not believe that they should have to wear headgear, most (62\%) agreed or agreed strongly that its use may prevent concussion. This was consistent across three of the teams, but half of the players on the university team were undecided, with a smaller number in agreement (29\%).

Most players $(81 \%)$ disagreed or disagreed strongly that headgear use could lead to an increase in concussion, with only $14 \%$ undecided and $5 \%$ in agreement with this statement. This trend was consistent among all four teams, with most players in each team reporting that they disagreed or disagreed strongly.

There were a number of reasons for not always wearing headgear, and the players were asked to rank their top three (table 1). The most popular was that headgear use is not mandatory, followed by not comfortable and expensive. Other popular reasons were poor ventilation and "it gets grabbed during play".

\section{Coaches' attitudes to safety gear}

In general, the coaches were less convinced than the players that headgear could potentially minimise the risk of concussion. Five of the nine coaches did not think that the use of protective headgear reduces the incidence or severity of concussions, one coach was undecided, and three believed that headgear is effective. Some coaches who did not believe that headgear is effective in preventing concussion suggested that its use could potentially lead to more concussion as the players may: "have a false sense of security"; "learn to lead with their heads"; or even "take a kamikaze approach". They

Table 1 Players' reasons for not always wearing headgear to play rugby

\begin{tabular}{lc}
\hline Reasons & Total \\
\hline Not mandatory & 25 \\
Uncomfortable & 24 \\
Cost too much & 18 \\
Poor ventilation/too hot & 17 \\
Gets grabbed during play & 13 \\
Other (e.g. hard to hear) & 11 \\
Rest of team do not wear it & 8 \\
Poor fit & 8 \\
I don't like the looks & 8 \\
Too difficult to obtain & 7 \\
Others might make fun of me & 4 \\
Not aware that it is available & 3 \\
\hline \multicolumn{2}{l}{ Total represents the number of players who } \\
included the associated reason in their top three \\
ranked choices.
\end{tabular}


were concerned that padding in rugby may evolve to that currently used in American football. Apart from potentially leading to more injuries, the coaches were worried that the cost of playing rugby would also increase.

\section{DISCUSSION}

This investigation produced some interesting findings. Firstly, most players believe that headgear can minimise the risk of concussion and its use does not potentially lead to an increase in concussions. This finding is in accordance with the Australian study by Finch et al, ${ }^{19}$ which reported that over $50 \%$ of players believe that wearing headgear can prevent head injury. Secondly, despite their beliefs that headgear can prevent concussion, most players do not wear it, nor do they think its use should be made mandatory. In contrast with the Australian study, ${ }^{19}$ which reported that over $60 \%$ of their teenage players wear headgear, this study showed that only $26 \%$ of the Canadian high school players reported wearing headgear. Thirdly, coaches appeared to be less convinced than players that headgear may be effective in preventing concussion, although opinions were varied. Interestingly, coaches were more inclined than the players to believe that the use of headgear could potentially lead to more injuries.

The limitations of this study include $(a)$ the lack of use of a truly random sample of participants and $(b)$ the inability to ensure full informed consent by the players because the coaches/trainers distributed the questionnaires. With regard to the first limitation, time and monetary restraints necessitated the use of a rather small sample size. However, a sample as representative of Canadian rugby players and coaches as possible was used. Subjects were included from both sexes, from different geographical areas (Victoria, British Columbia and Toronto, Ontario), and from four levels of play (high school, university, community club, national). Although inclusion of participants differing with respect to these variables makes the sample more heterogeneous and thereby more reflective of the Canadian population of coaches and players, the lack of a truly random sample (and the small sample size) limits our ability to generalise pertinent findings to all rugby players and all rugby coaches in Canada. With respect to the second limitation, explicit instructions were given to the coaches/trainers with regard to obtaining informed consent from the players. However, it was almost impossible to ensure that truly informed consent was obtained from each player. If resources had allowed, the researcher would have personally met each team (in the absence of the coach) to explain the purpose of the study and emphasise that participation was entirely voluntary and anonymous.

Despite these limitations, a number of recommendations can be made from the pertinent findings of the study. Firstly, it is the author's belief that further research is required to determine whether headgear can, indeed, minimise the risk of concussion, or alternatively, lead to an increase in concussions. This may be achieved through a longitudinal study in which the rate of concussion is compared between those who wear headgear and those who do not. In fact, the need for this type of research has previously been recognised. ${ }^{17}{ }^{19}$ Secondly, better education and communication is needed. Although there has been a dearth of studies on the protective role of headgear, players and coaches have developed their own beliefs in this regard. We need to make the public aware of research results (and lack thereof) so that informed choices and recommendations can be made with respect to wearing headgear. Thirdly, the attitudes of players to safety gear need to be examined. In particular, it is important to know why players do not feel that headgear should be made mandatory given their belief that it can protect against concussion. Insight into this may help in the development of health promoting attitudes in this population. Fourthly, there is a need for better design and lower cost

\section{Take home message}

Although most of the players in this study believe that headgear may prevent concussion, the coaches are less convinced, and tend to believe that its use could lead to more injuries. As concussions can potentially impair cognitive functioning and general wellbeing, further research into methods of prevention, including the effectiveness of headgear, is imperative.

of headgear. As this study shows, some of the reasons for not wearing headgear were: it is uncomfortable, has poor ventilation, makes it hard to hear, and costs too much. Perhaps if these problems were addressed, more players would choose to wear headgear. Finally, players should be given appropriate information on concussion. They should be made to realise that repeated concussions may place them at increased risk of cognitive impairment if they continue to play. This risk exists whether or not headgear is worn.

\section{Conclusions}

Rugby is a contact sport in which the potential for concussion is high. Concussion may, at least temporarily, ${ }^{4-8}$ and perhaps permanently, ${ }^{9-14}$ impair aspects of cognition. It seems imperative therefore that attempts should be made to prevent, or at least minimise, their occurrence. One way to reduce concussions is through the use of protective safety gear. Although most players in this study believe that headgear can protect against concussion, they are reluctant to wear it. The development of more effective headgear and the examination of the potential for headgear use to actually increase injury rates (a concern expressed by the coaches in this study) both warrant further consideration. Other possible strategies to minimise the risk of concussion in rugby players, such as rule changes, should also be explored.

\section{ACKNOWLEDGEMENTS}

This study was funded through The Office for Injury Prevention at Sunnybrook \& Women's College Health Sciences Centre, Toronto. I wish to thank the following people for their assistance: Joanne Banfield, Coordinator of the Office for Injury Prevention, Dr J Preston Wiley, Canadian Rugby Union physician, and, of course, all of the participants

\section{REFERENCES}

1 Roy SP. The nature and frequency of rugby injuries: a pilot study of 300 injuries at Stellenbosch. S Afr Med J 1974;2:2321-7.

2 Kelly JP, Rosenberg JH. Diagnosis and management of concussion in sports. Neurology 1997;48:575-80.

3 American Academy of Neurology. Report of the Quality Standards Subcommittee. Practice parameter: The management of concussion in sports (summary statement). Neurology 1997;48:581-5.

4 Gronwall D. Minor head injury. Neuropsychology 1991;5:253-65.

5 MacFlynn G, Montgomery EA, Fenton GW, et al. Measurement of reaction time following minor head injury. J Neurol Neurosurg Psychiatry 1984;47:1326-31.

6 Gentilini M, Nichelli P, Schoenhuber R, et al. Neuropsychological evaluation of mild head injury. J Neurol Neurosurg Psychiatry 1985:48:137-40.

7 Newcombe F, Rabbitt P, Briggs $M$. Minor head injury: pathophysiological or iatrogenic sequelae? J Neurol Neurosurg Psychiatry 1994;57:709-16

8 Mariadas AC, Rao SL, Gangadhar BN, et al. Neuropsychological functioning in postconcussion syndrome. NIMHANS Journal 1989:7:37-41.

9 Gronwall D. Cumulative and persisting effects of concussion on attention and cognition. In: Levin HS, Eisenberg HM, Benton AL, eds. Mild head injury. New York: Oxford University Press, 1989:153-62.

10 Gronwall D, Wrightson P. Cumulative effect of concussion. Lancet 1975;2:995-7.

11 McLatchie G, Brooks N, Galbraith S, et al. Clinical neurological examination, neuropsychology, electroencephalography and computed tomographic head scanning in active amateur boxers. J Neurol Neurosurg Psychiatry 1987;50:96-9.

12 Matser EJT, Kessels AG, Lezak MD, et al. Neuropsychological impairment in amateur soccer players. JAMA 1999;282:971-3. 
13 Collins MW, Grindel SH, Lovell MR, et al. Relationship between concussion and neuropsychological performance in college football players. JAMA 1999;282:964-70.

14 Pettersen JA, Skelton RW. Glucose enhances long-term declarative memory in mildly head-injured varsity rugby players. Psychobiology 2000;28:81-9

15 International Rugby Board (IRB). Law 4M-98g. Standard performance specification for specific items of players' clothing. Dublin: International Rugby Board, 1996.
16 Gerrard D, Waller A, Bird Y. The New Zealand Rugby Injury and Performance Project. II. Previous injury experience of a rugby-playing cohort. Br J Sports Med 1994;28:229-33.

17 Wilson BD. Protective headgear in rugby union. Sports Med 1998;25:333-7

18 McIntosh AS, McCrory PM. Impact energy attenuation performance of football headgear. Br J Sports Med 2000;34:337-41.

19 Finch CF, Mclntosh AS, McCrory PM. What do under 15 year old schoolboy rugby union players think about protective headgear? $\mathrm{Br}$ Sports Med 2001;35:89-94.

\section{BASEM Merchandise 2002}

Ties

Multi motif

$£ 6+£ 1.50 p \& p$

New stock to order

Sweaters

Lambswool fine knit, V-neck or round

$£ 32+£ 3 p \& p$ neck with small motif. Machine washable.

State colour and chest size required.

Sweatshirts

With small motif.

State colour and chest size required.

Polo shirts

With small motif.

$£ 25+£ 3 p \& p$

State colour and chest size required.

$£ 23+£ 3 p \& p$

Send orders to John H Clegg JP BSc (Hons) DipEcon (Open) LDS RCS Eng, Hon Secretary, Birch Lea, 67 Springfield Lane, Eccleston, St Helens, Merseyside WA10 5HB, UK. (Tel and Fax: 01744 28198) 